\title{
concerning publicized goods \\ (or, the promiscuity of the public goods argument)
}

vaughn bryan baltzly

texas state university

september 7, 2020

Proponents of the public goods argument seek to ground the authority of the state, and the scope of its legitimate activity, on its putative indispensability as a means of providing public goods. But many of the things we take to be public goods-including many of the goods commonly invoked in support of the public goods argument (hereinafter 'PGA')-are actually what we might term publicized goods. A publicized good is any whose 'public' character results only from a policy decision to make some (otherwise private) good freely and universally available, rather than from any features that are (we might say) inherent in or intrinsic to the good itself. This fact poses complications for proponents of the PGA, insofar as the set of possible publicized goods-and thereby the set of all public goods-is quite extensive indeed. In this paper, I explore these complicationsfirst by offering some reflections on public goods and the PGA as traditionally conceived, second by providing some observations on the processes whereby ordinary private goods may be 'publicized', and third by commenting on the resultant 'promiscuity' of the PGA. I conclude by briefly sketching two possible frameworks for theorizing state provision of public(ized) goods that can accommodate the challenges posed by the possibility of publicization and the concomitant problem of promiscuity.

\section{Concerning Public Goods}

What, exactly, are 'public goods' in the sense relevant here? Whatever else they are, public goods are nonexcludable. That is, a public good is one such that, once provided, it is impossible (or at least prohibitively costly) to exclude any persons from enjoying or 'consuming' said good, whether or not they have paid for it. Most writers insist that public goods bear other features as well. It is currently fashionable to further characterize public goods as being also non-rivalrous. ${ }^{1}$ A good is non-rival-or exhibits 'non-rivalry in consumption'-when any one party's enjoyment of said good does nothing to diminish any other party's enjoyment of the good. Other theorists-particularly those writing more than a few decades ago-supplement

\footnotetext{
${ }^{1}$ See, e.g., Cowen [2008: 197], and Anomaly [2015: 109]. For further evidence that characterization in terms of both non-excludability and non-rivalry represents something like the prevailing consensus, the interested reader is invited to consult any of a number of standard Internet reference sources. For example, see (together with the references incorporated therein) the Wikipedia entry on public goods (available at https://en.wikipedia.org/wiki/Public good [accessed November 2, 2019])-particularly the 2x2 'definition matrix' found in Section 1.1 (a matrix which traces back to at least Ostrom and Ostrom [1977])-or the entry on Encyclopedia.com (available at https://www.encyclopedia.com/social-sciences/dictionaries-thesauruses-pictures-and-press-releases/public-good [accessed November 2, 2019]). The same evidence could be ascertained by consulting any of a variety of introductory microeconomics textbooks.
} 
the non-excludability requirement, not with the non-rivalry condition, but with that of indivisibility. ${ }^{2}$ A good is indivisible insofar as it cannot be divided into discrete units that are then provided to individual consumers.

Non-rivalry and indivisibility are similar and related notions, but it is worth noting the distinction between the two. As Michael Taylor puts it, "Where there is some degree of divisibility, consumption reduces the amount available to others; but where there is some degree of rivalness, consumption reduces the benefits to other consumers' [1987: 7, emphasis in the original]. The distinction can be seen most clearly by considering the phenomenon of crowding, or congestion. A good may be perfectly indivisible-consumed in equal 'quantity' by every member of the relevant public-yet still exhibit rivalry in consumption insofar as each additional individual's consumption of the good introduces congestion effects that diminish the degree to which some (or all) individuals enjoy the good.

Though non-rivalry and indivisibility are the two features most commonly conjoined with non-excludability as representing the distinguishing characteristics of a public good, the earnest student of political economy will also notice other concepts sometimes put forward as part of this definition. In most cases, however, these concepts seem to be indistinguishable from that of indivisibility. This seems to be the case for 'subtractibility' (as in Ostrom and Ostrom [1977]), 'jointness of supply' (as in Mueller [1989]), and 'non-depletability' (as in Baumol and Blinder [2006: 312-13]). The Encylopedia.com entry on public goods cited above also includes, along with non-excludability and non-rivalry, the 'impossibility of rejection' as one of a public good's three essential characteristics.

Notwithstanding this diversity of opinion with respect to which further feature(s) serve(s) to distinguish them, the relevant body of literature in political economy exhibits striking uniformity in taking non-excludability to be an essential feature of public goods. (Samuelson [1954] is widely cited as the origin of the modern conception of public good under investigation here, and so the relevant body of literature is plausibly 65 years old. The phrase Samuelson there employs, though, is actually 'collective consumption good'. The phrase 'public good' likely traces to Samuelson [1955: 350], where he introduces the term 'public consumption good.') It therefore seems safe to regard non-excludability as the common core of all authors' usage of the term. Thus, we will henceforth use the term 'public good' to refer to any non-excludable good whatsoever, irrespective of its (in)divisibility, its (non-)rivalry, or its what-have-you. Readers uncomfortable with this (admittedly somewhat stipulative) definition may simply substitute 'non-excludable good' for every

\footnotetext{
${ }^{2}$ See, e.g., Head [1962: 201], Rawls [1999: 235-7], Hampton [1987: 242], Taylor [1987: 5-6], and Mueller [1989: 11].
} 
appearance of 'public good' in what follows; such readers should find that the force of the arguments remain substantially unchanged by this interpretation. ${ }^{3}$

\section{Concerning the PGA}

Their non-excludability is thought to render public goods unsuitable candidates for market provision. This is owing to the market failure that is said to hamper the spontaneous marketplace provision of public goods by private actors responding to ordinary market incentives. As a result of various collective-action problemsmost notably, the free-rider problem and the assurance problem ${ }^{4}-$ non-excludable goods are thought to be under-provided (if provided at all) in the marketplace. ${ }^{5}$

If public goods are unsuitable candidates for marketplace provision, though, they may well be-or may therefore be-the proper objects of state provision. Hence the PGA, according to which the state is required (and morally justified) as a sort of deus ex machina necessary to produce these public goods for a populace prepared to consume them (and even to pay for them), but otherwise thwarted in its efforts to do so by the stubborn persistence of collective action problems. (Never mind, for now, the fact that the creation of the state itself poses a collective action problem. ${ }^{6}$ ) This series of claims is often thought to constitute a kind of argumentative maneuver, though it does not yet represent a comprehensive argument. Relatively few authors put the 'A' in the 'PGA'; the 'argument' per se is typically left implicit at best. (It is perhaps no accident, then, that the phrase 'public goods justification of the state' seemingly appears in the relevant literature with equal, if not

\footnotetext{
${ }^{3}$ We might note that our decision to identify non-excludability as public goods' sole distinguishing feature is not without at least one respectable precedent. In a preeminent technical economic analysis of public goods, Cornes and Sandler [1996: 9] write that 'nonexcludability is the crucial factor in determining which goods must be publicly provided.'

${ }^{4}$ Readers interested in learning more about these two forms of market failure in the context of public goods provision could do little better than to consult chapter 4 of Schmidtz [1991]. Readers wishing to dive even more deeply should know that Cornes and Sandler [1996: 30] point out that ' $[t]$ he term free rider, which is used rather loosely in the literature, applies to at least three distinct phenomena .... They furthermore note that 'free rider' is, '[s]tricly speaking ... a misleading term, because agents seldom ride completely free ... The term easy riding is more appropriate for the suboptimality associated with pure public good provision, since it does not imply zero provision'. However, we can safely ignore these complications in what follows.

${ }^{5}$ However, some authors argue that these market failures can be overcome, and that non-excludable goods can be provided in response to market-like incentives. This position is central to the anarcho-capitalist line of thought (see, e.g., Taylor [1987], Hasnas [2008], and Huemer [2013]). Schmidtz [1991] explores the use of, e.g., 'assurance contracts' with unanimity conditions as a way of surmounting these sorts of collective action problems. Furthermore, other authors have argued that the picture of the rational utility-maximizing Homo economicus underlying this whole picture is irreparably flawed as a description of actual human beings. For one overview of some experimental work that may undermine this picture, see Ostrom [2000].

${ }^{6}$ This is sometimes referred to as the 'circularity problem' (as in Cowen [2003]), or as 'premarket market failure' (as in Coleman [1985]). Cowen's paper provides an instructive overview of this challenge, along with several possible solutions. Furthermore, several recent authors have emphasized that the ongoing maintenance and oversight of the state, no less than its initial creation, is also something of a public good, posing its own collective action problem. (Expressed in terms of a democratic polity: because the data-gathering and information-processing tasks attendant to the duty of voting wisely are costly, and because I will benefit from my neighbors' wise votes whether or not I myself vote wisely, I seem to have incentive to free-ride on my neighbors' efforts to this effect.) For a recent development of this insight, and a forceful articulation of the challenge it poses for public goods-based arguments for the state, see Freiman [2017: chp. 1].
} 
greater, frequency.) Many economists, for example, seemingly do little more than to simply note the existence of market failure with respect to public goods, and then conclude that the presence of these market failures suggests the propriety of state provision of public goods. Representative theorists who more or less perform this hand-waving maneuver include: Samuelson [1954] and [1955], Head [1962: 200], and Mueller [1989: 9]. Nor are political philosophers immune from this defect of 'implicit argumentation': even Rawls [1999: 235. 6] makes a similarly pithy, passing remark on this score, when he writes that ' $t$ ]he consequence of indivisibility and publicness in these cases is that the provision of public goods must be arranged through the political process and not through the market'.

The passage from Rawls just cited is representative in this respect; typically, the PGA appears in merely elliptical fashion. It often appears as an either tacit or express appeal to what we might call the

Paraphrase: 'Markets won't supply public goods, so governments have to.'

Unfortunately, Paraphrase is as vague and ambiguous as it is commonplace. Nevertheless, if we are to properly evaluate the PGA, we must give it a more precise rendering so that its structure can be seen more explicitly. One way of disambiguating the argument implicitly embedded in Paraphrase would be to spell out its (suppressed) quantifiers in the following fashion: 'Markets won't provide any public goods, so governments must step in to provide all of them.' Let us formalize the argument that seems implicit in this disambiguating rendering of the common Paraphrastic version of the PGA:

Premise (1): Due to market failures (originating from collective action problems), markets will undersupply public goods (if they supply them at all).

Premise (2) [conclusion from (1)]: Government intervention is therefore required in order to ensure provision of public goods.

Premise (3): It is a good thing to have public goods.

Conclusion: Governments should therefore intervene so as to ensure the provision of public goods.

Let us term the foregoing the 'Folk PGA'. Admittedly, the Folk PGA is not the only-or even the most plausible or most charitable-available rendering of Paraphrase. Nor does it yield the strongest or most sophisticated formalized version of the PGA that one might articulate. However, I cannot say with confidence that, when many writers allude to the 'public goods argument' or the 'public goods justification' for the state, they don't have approximately the Folk PGA in mind. Nor does it seem unlikely that this is substantially cruder than what passes for the PGA in what (following Huemer [2013: xxvii]) we might call the 'oral 
tradition' within political philosophy. So, for these reasons-and notwithstanding any shortcomings it might have-it behooves us to give at least brief consideration to this version of the PGA.

The Folk PGA suffers from several obvious defects. For one thing (and as already mentioned in note 5 above), many writers dispute Premise (1)-for example: Taylor [1987], Hampton [1987], Schmidtz [1991], Hasnas [2008], Huemer [2013]-and therefore (2) (and all waystations required to get there) as well. For another thing, the move from (1) to (2) seems to presuppose something like (1.1) 'Government intervention is the only solution to market failure(s)' (otherwise, to conclude (2) from (1) is to commit something like the False Dilemma fallacy) and (1.2) 'We should seek to remedy any and all market failure(s).' And obviously, the move from Premise (3) to the Conclusion seems to rely on a suppressed Premise (3.1)-something to the effect of 'If there is a good thing that only a government could do, then that government should do it.' However, leave these matters to one side for now. This schematization is sufficient to highlight the most glaring weakness of the Folk PGA: the utter implausibility of Premise (3). For Premise 3 renders the Folk PGA problematically promiscuous. In its attempt to delineate the proper scope of state authority, that is, this argument licenses far too much. The PGA's proponents cannot argue that the state ought to provide just any public good, or every public good-for the set of non-excludable goods is quite extensive, and many of its members are (at best) controversial or (at worst) manifestly unsuitable, or even unsavory, candidates for state provision. (Consider the following examples: Confederate monuments, a pervasively-lilac-scented atmosphere, a free Nazi Museum in Tel Aviv. ${ }^{7}$ ) It seems, therefore, that any fully-fledged version of the PGA must also include a worthiness criterion specifying which non-excludable goods the state ought to provide.

To be sure, previous writers have noticed the potential promiscuity of the PGA, and have formulated various strategies for responding to it. As Jonathan Anomaly [2018: 117] pithily expresses it, 'there is no automatic connection between public goods and state action'. And in a previous paper, this same author provides a helpful compendium of strategies for responding to the promiscuity problem. As Anomaly expresses it there, '[t]he problem is how to determine which public goods government should supply' [2015: 112]. To this end, he sketches seven considerations that 'theorists and policy makers should ask when confronted with prospective public goods' (p. 111), considerations that might help us to demarcate the class of worthwhile public goods that truly merit state provision. These considerations include the extent and stability of public demand for the good in question, whether the benefits supplied by that good would be fairly distributed, and whether or not provision of the good in question would be paternalistic or otherwise morally objectionable. But perhaps the most important consideration he discusses is his third: whether or not 'the benefits of providing the good exceed the costs of provision' (p. 112).

\footnotetext{
${ }^{7}$ This latter example is borrowed from Anomaly [2015: 112 (inclusive of note 5)].
} 
This, of course, is simply an invocation of the famous technique of cost-benefit analysis (CBA) as a worthiness criterion for adjudicating which public goods are worth the effort and cost to provide. With this appeal, the PGA's proponents standardly argue that the state should supply all and only those non-excludable goods whose benefits exceed the costs (including the opportunity costs) of their public provisioning. In making this appeal, we might say that the PGA's proponents are invoking the cost-effectiveness criterion of worthiness.

Most theorists working in the field of public finance-for example, Musgrave [1959], Baumol [1965], and Buchanan [1968]-employ just this sort of consequentialist, CBA-centered framework in their treatments of these issues. In one classic discussion, for example, Baumol [1965: 21] briefly summarizes what we here call the PGA before writing that it is 'not intended as a justification for the automatic provision of every potential public good. In each case, before a decision is made to allocate resources to such an output, its anticipated benefits must be compared most carefully with its costs, including the opportunity costs of the resources which must be used in its production.' The authors in this tradition typically note that markets under-supply various sorts of goods and services (including, though not always limited to, public goods: Musgrave [1959: 13-14], for example, also discusses what he coins as 'merit goods' in this regard), and then aver that some sort of public provision of these under-supplied goods is therefore necessary. And they will typically immediately proceed to acknowledge (stress, even) that the decision as to which such goods warrant public provision presents certain practical challenges. These challenges are often conceived as various technical difficulties attending to the tasks of eliciting and aggregating individual consumers' true utility functions with respect to various collective goods-tasks performed for purposes of ascertaining whether the social benefits of such provisionings would truly exceed their costs. ${ }^{8}$ (An example of one such technical difficulty: how could we get 'citizen-consumers' to accurately reveal the strengths of their preferences-or their 'willingness-to-pay'-for various public goods on, e.g., various survey instruments, given that these respondents would have strategic reasons for concealing or downplaying their preferences, or for understating their willingness to pay?) Nevertheless, the clear implication is that, notwithstanding these practical difficulties, the problem of promiscuity poses no theoretical challenge: the state ought to provide all and only the 'cost-effective' public goods. (Or, at very least, the state ought to provide all and only those cost-effective non-excludable goods whose provision does not run afoul of other considerations or principles-moral or otherwise-that might independently constrain the state's activities. Perhaps the state should not provide any public goods-not even tremendously cost-effective ones-the provision of which necessitates the violation of any citizens' rights.)

\footnotetext{
${ }^{8}$ Though these challenges are frequently acknowledged, they're seldom much more than that: with the exception of perhaps only Buchanan [1968], systematic treatment is not usually forthcoming.
} 
When we augment the Folk PGA's third premise with the cost-effectiveness criterion of worthiness, we get what we might call the 'Worthy PGA':

Premise (1): Due to market failures (originating from collective action problems), markets will undersupply public goods (if they supply them at all).

Premise (2) [conclusion from (1)]: Government intervention is therefore required in order to ensure provision of any public good.

Premise (3): It is a good thing to have public goods. Government provision of certain public goods is cost-effective: that is, the social benefits of their public provisioning exceed their social costs.

Conclusion: Governments should therefore intervene so as to ensure the provision of any such public goods.

The Worthy PGA is worthy of our sustained examination. At first blush, it dispenses with the promiscuity problem that plagues the Folk PGA. But as we'll see shortly, the Worthy PGA is still bedeviled by the possibility of publicization (explored more fully in section 3). For this possibility saddles the Worthy PGA with a new version of the promiscuity problem (explored more fully in section 4) that is resistant even to the CBAcentered cost-effectiveness criterion that is built into the Worthy PGA's third premise. Let us now turn to these matters.

\section{Concerning Publicization}

Public goods are potentially ubiquitous: it's not that they're everywhere, it's that they're anywhere. Take (virtually) any good you like; for now, I'll take high-speed wireless Internet access (hereinafter 'WiFi'). WiFi might seem to you to be a paradigmatically private good. But watch: I will convert it to a paradigmatically public good by appending the prefatory phrase 'guaranteed universal access to': 'guaranteed universal access to WiFi'. Voila! A brand-new public good. Call any private good thus converted into a public good a 'publicized good', and call this process of conversion 'publicization'.?

\footnotetext{
${ }^{9}$ Technically, the 'publicization' of WiFi does not involve its conversion from a private good into a public good. The newly-created public good is not WiFi per se; rather, what's happened is that a wholly new good has been created-viz,, guaranteed universal access to WiFi. This new good is a form of assurance, and the entity creating it is not (necessarily) the Internet Service Provider whose physical infrastructure provides wireless Internet access to individual users; the entity creating it is whomever is effecting the guarantee. Call this entity (whether private or public) the 'guarantor'. Thus, to say that the guarantor has in this instance 'publicized the (formerly private) good of WiFi' is to speak too loosely. In fact, what this guarantor has created is (to introduce a helpful formalism) a newly-publicized good $G$, and the means it has employed to do so is to guarantee universal access to some private good g. In what follows, however, we can ignore this complication, and simply speak of 'publicizing some (private) good' as a convenient shorthand for 'creating some novel good $\mathrm{G}$ by guaranteeing universal access to some good $g$ '.
} 
According to the PGA's many proponents, the state exists to provide public goods. Which are the public goods? A central contention of this paper is that, in principle, any of them might be-all private goods are liable to publicization. And the central contention of the present section is that, in fact, many goods already have been. That is to say: once aware of the possibility of publicization, we notice that a wide array of the public goods discussed in the literature-including, crucially, many of the goods commonly invoked in support of the PGA-are not in fact inherently public goods, ${ }^{10}$ but are actually publicized goods. Take (virtually) any public good you like; for now, I'll take the social safety net. The social safety net might seem to you to be an inherently public good. But watch: a bit of analysis reveals that it consists entirely of goods that are, in and of themselves, quite excludable.

We shall begin this analysis with a diagnosis of the pervasive failure to recognize the publicized nature of this good. The naturalness of conceiving the social safety net to be an inherently public good derives largely, I suspect, from the analogy suggested by the very phrase (itself metaphorical) used to denote the good in question. Let us develop the image suggested by the term 'social safety net' by considering what we might term the 'tightrope analogy'. Imagine a population of individuals, each of whom must cross a canyon on a tightrope. A safety net at the bottom of the canyon would be an inherently public good for this population. Once provided, it's there to catch anyone and everyone who falls; there is no feasible way to exclude any tightrope-walking individual from benefiting from its services. (It's in the nature of safety nets, we might imagine, that they're too cumbersome and unwieldy to erect or dismantle at a pace that's responsive to the identity of the individual walking the tightrope at any given moment.)

But is the social 'safety net' relevantly similar to an actual safety net? Are there similarities that sustain the judgment that a social safety net (composed, perhaps, of guaranteed retirement income and the assurance of means-tested monetary benefits available upon properly-documented instances of, e.g., unemployment, disease and disability, natural disaster, etc.) is really an inherently public good? Is it a public good on par with, say, clean air and national defense (two paradigmatic instances of inherently public goods)? The answer depends on whether we judge such social insurance provisions to be non-exclud-able, or simply un-exclud-ed. And in fact, it seems that even to pose the question in this manner is to recognize that it is the latter. For it

\footnotetext{
${ }^{10}$ We may think of 'inherently public goods' as those whose non-excludable character does not depend solely on a public policy designed to ensure guaranteed universal access to some private good-that is, they are those goods that are 'inherently' or 'intrinsically' non-excludable. Kenneth Goldin [1977: 55] goes further, denying that the 'publicness' of any good results from properties that are inherent or intrinsic to that good-averring instead that the non-excludability of any putative public good is always actually only the consequence of a policy decision. As he puts it, 'there are no goods or services which are inherently public goods or externalities; ... there is always a choice between equal and selective access' (emphasis in the original). We need not take a position with respect to this 'strong[er] theorem'-which Goldin himself concedes 'could never be proven'-in order for the present argument to succeed. We need only recognize that a great many so-called 'public goods' are in reality publicized goods, whether or not there are some others that are inherently non-excludable.
} 
seems clear that a social safety net comprises goods-for example, cash payments-that are after all quite excludable. Any individual's coverage under such an insurance scheme could be made contingent upon her agreeing to pay certain premiums. In this way, the good of a safety net can be provided privately, just as private entities provide citizens with all manner of insurance policies in all manner of domains. (To return to our analogy, we can imagine canyon-crossing individuals as purchasing 'personal netters'-teams of retired firemen, for instance, who track just their movements across the tightrope, and who utilize their expert netpositioning skills to catch the individual in the event of a fall. Perhaps this option is attractive because the nets in question can be customized according to the individual's personal net-preferences and budget constraints. Or maybe the 'net' in question could most efficiently take the form of a simple (automaticallydeploying) parachute.) So strictly speaking, it seems a social safety net isn't an inherently public good after all-it fails to meet the non-excludability condition. ${ }^{11}$

So much for social safety nets; matters stand likewise with another oft-cited public good: public parks. Consider, first, that there is nothing in the nature of parks that renders them inherently non-excludable: it is easy enough to build a gated fence to enclose a park built on private land, and to employ guards to collect admission from anyone wishing to pass through those gates. But such a park wouldn't be a public park-one whose fresh air and green space are (assured to be) open and available to all. In this manner, a public park is another paradigmatic instance of a (potentially private) good that has been publicized, in the fashion described above.

\footnotetext{
${ }^{11}$ At this point, one might note that the benefits available under most social insurance schemes are means-tested, and one might thus conclude that 'social insurance' is not a public good after all, insofar as it is quite excludable. (After all: those who don't meet the eligibility requirements-those whose incomes are above a certain threshold, e.g.-are excluded from receiving these benefits.) But this is a mistake: the presence of means-testing does not betoken excludability or exclusion. For the social safety net's assurance of (e.g.) income-supplement, if and when times get tough, is one that is provided to all. It's the assurance (or, one might say, insurance) that is the basic (public) good in question, not the actual payments disbursed thereunder. Thus, different individuals' differential utilization of actual social-insurance payments is irrelevant to the analysis of social insurance as a public good: each individual 'consumes' the social insurance equally, and this is the relevant fact. Consider an analogy with private insurance: we don't say that folks fortunate enough never to experience a flood are 'excluded' from receiving the insurance pay-outs promised by their flood insurance policy. Or consider an analogy with another public good: the system of law enforcement and criminal justice. The court system is there for everyone, and all alike enjoy the assurance that-should the need ever arise-they can redress wrongdoing and injury through a fairly effective, efficient criminal- and civil-justice system. Many citizens will be fortunate never to have to file civil or (participate in a) criminal suit, but that doesn't mean they don't 'consume' the benefit of having it there. In fact, the deterrent effect that the effective functioning of this system provides, vis-à-vis would-be criminals and aggressors, is something citizens consume every day, if they are fortunate enough to go about their daily affairs unmolested by the intrusion and aggression of their neighbors. And just as well-functioning criminal justice and legal systems have this legal 'assurance effect', so also should a well-functioning social safety net provide an economic assurance effect. Many productive economic endeavors and enterprises will go better-or will go at all-if citizens are secure knowing that, in the advent of joblessness or the failure of their venture capital schemes, there is an adequate economic safety net to catch them. Few but the most intrepid would venture out on that tightrope, after all, if that net weren't there.
} 
So neither the social safety net nor public parks are inherently public goods. Rather, these are publicized goods. And presumably similar analyses could be conducted for a range of other much-discussed public goods-such as public highways, bridges, and ports. Whence, then, the pervasive tendency to regard these as public (even, some might say, 'paradigmatically public') goods? I suspect it has to do with the names by which they're commonly known: the social safety net, and public parks. In fact, for ease of exposition, we might decide to abbreviate the four-word prefatory publicizing phrase ('guaranteed universal access to') as, alternately, 'public' or 'social': 'public WiFi', e.g. And in fact, we might even speculate that the frequent appearance of these abbreviated modifiers in the phrases widely used to denote what are in reality publicized goods-'public parks' and 'social safety nets'-suggests an at least implicit, widespread grasp of the nature of publicization, and an at least tacit recognition that the maneuver has taken place. ${ }^{12}$ By contrast, in the case of inherently public goods (in our stricter sense), one searches in vain for references to 'public clean air', 'social rule-of-law', or 'public geographical military deterrence'.

Two brief remarks are required before we proceed to consider the implications of the possibility of publicization for the plausibility of the PGA. The first is to note that there may be additional 'publicization maneuvers' besides the one noted above. At the outset of this section, I demonstrated how one may publicize any private good by appending to its name or description the four-word prefatory modifier 'guaranteed universal access to'. However, there is at least one alternative maneuver one might perform. For sometimes what we desire is not universal access to a good; sometimes what we desire instead is universal consumption of a good. Thus, besides appending 'guaranteed universal access to' before the description of any private good, another strategy is to append the phrase 'guaranteed universal consumption of. ${ }^{13}$ (We should recognize that it will often seem more natural to render this alternative maneuver in the fashion 'universally prescribing behavior $b$ ', rather than in the fashion 'universally prescribing consumption of good $g$ '. This recognition raises certain complications, however, which are best ignored for present purposes.) This accounts for what's going on with a number of what are sometimes (and somewhat misleadingly) called hybrid goods-for example,

\footnotetext{
${ }^{12}$ Note, however, that the presence of said prefatory modifiers is not necessarily evidence that the referent of the thusprefaced phrase is a publicized good. Often, it merely signals the existence of a publicly-funded private good, as is the case with 'public utility' or (when the socially-beneficial spillover effects of its research and education functions are ignored) 'public university'. This ambiguity in the function of the 'public' preface sometimes occasions confusion, as people frequently equivocate in the following manner: 'Public universities are a public good; governments are in the business of supplying public goods, so therefore governments ought to supply (more (money to)) public universities.' Note that equivocating in this fashion generates the following peculiar result: once a state funds any good X, the provision of that good becomes (irrespective of one's antecedent commitments with regard to the propriety of the state's funding of X) a legitimate object of state activity-for X becomes, ipso facto, a public good, and states are after all 'in the business of supplying public goods'.

${ }_{13}$ Or, because it may not be strictly universal consumption that we desire, but only an adequate general level of consumption, we might formulate this instead as 'guaranteed widespread consumption of. Of course, a similar modification can be made to our initially-contemplated publicization maneuver: we need not countenance only 'guaranteed universal access to'; perhaps we might also countenance 'guaranteed widespread' (or 'guaranteed sufficiently widespread') access to a private good.
} 
vaccinations. These goods are thought to be 'hybrid' insofar as they have both public and private dimensions simultaneously. A hybrid good bears 'private' benefits, which redound to individual consumers. Yet at a certain point, once consumption of this good becomes sufficiently pervasive, further 'public' benefits (we might refer to them as 'spillover effects' or 'positive externalities') redound to everyone equally. (Depending on the good in question, the required level of pervasiveness here may be closer to, or further from, universality. For vaccinations, this public benefit redounds once the threshold of herd immunity is reached.) Insofar as the good offers private benefits, market mechanisms will tend to ensure provision of the good at levels adequate to equilibrate supply with 'natural' demand. But insofar as the population's widespread consumption of this good (sufficient to exceed the 'threshold of adequate pervasiveness', such as with the herd-immunity threshold) yields collective benefits, there is a public goods component to ensuring that this threshold is met. If 'natural' demand is adequate only to elicit supply below this threshold, then there may be incentive for a 'guarantor' to intervene and 'artificially' augment demand until it reaches the point at which the quantity supplied (and consumed) is now above-threshold. The guarantor may perform this augmentation of natural demand by supplying incentives (e.g., discounts or side benefits to induce higher levels of voluntary consumption), or via mechanisms of enforcement (e.g., by mandating compulsory vaccinations)-together, perhaps, with subsidies for those who are unable to pay for their own (compelled) consumption of these goods. ${ }^{14}$ At any rate: market incentives are adequate to ensure market equilibrium visà-vis the private good of vaccines, but not the collective benefits of a fully-vaccinated populace. For the latter, the role of the guarantor is to ensure consumption of vaccines at a level sufficiently widespread to create herd immunity. Similar analyses could be provided for a range of other publicized goods-for instance, the publicized good of a well-educated populace. ${ }^{15}$

Second, we should remark that the possibility of publicization has not gone entirely unnoticed-even if it has been under-appreciated. As noted above, Goldin [1977] noticed it more than 40 years ago, in what (to my awareness) remains the most forceful presentation of the challenge it poses for traditional thinking about public goods. And besides Goldin, Mueller [1989] seems to recognize some version of the possibility of publicization. Mueller first defines public goods as having 'two salient characteristics: jointness of supply [i.e., indivisibility], and the impossibility [or] inefficiency of excluding others from its consumption, once it has been supplied to some members of the community [i.e., non-excludability]' (p. 11). But then on the next page he goes on to consider a slightly variant case: 'A $\mathrm{A}$ n alternative definition of a public good is that it may be provided in equal quantities to all members of the community at zero marginal cost. The substitution of

\footnotetext{
${ }^{14}$ Obviously, though, the compulsion mechanism will be available only to Sovereign guarantors-i.e., to the state. (That is, assuming we set aside as illegitimate cases of non-Sovereign compulsion, such as we sometimes observe with organized criminal syndicates like the Mafia.)

${ }^{15}$ For one recent analysis of education as a private good whose widespread 'consumption' yields certain public good-like positive externalities, see Anomaly [2018].
} 
"may" for "must" in the definition implies that exclusion may be possible. A classic example of a public good fitting this second definition is a bridge. In the absence of crowding, once built, the services of the bridge can be supplied to all members of the community, but they need not be. Exclusion is possible' (p. 12, emphasis in the original). In this fashion, Mueller seems to recognize that, even for inherently excludable goods, the process of affording or guaranteeing universal access to that good is, in effect, a way of creating a public good.

So much for our two additional remarks about the process(es) of publicization. Let us proceed at last to a consideration of the consequences of the possibility of publicization with respect to (what we have already termed) the 'promiscuity' of the PGA.

\section{Concerning Promiscuity}

The possibility of publicization renders acute the problem of promiscuity: viz., the challenge that, in attempting to delineate the proper scope of state authority, the PGA may license far too much. The PGA cannot justify the state in virtue of its role in providing just any public good, or in providing every public good-nor even in virtue of its role in providing just the cost-effective public goods-for as we have seen, any good can be publicized. Not even the Worthy PGA, with the cost-effectiveness criterion built right into its third premise, can handle this 'new-and-improved' problem of promiscuity-for, as we shall see presently, the technique of CBA upon which it relies proves computationally intractable in the face of publicized goods.

Most private goods could be publicized. Consider some of those that already have been (and which already have been mentioned in section 3): housing, nutritional assistance, various forms of social insurance (old ageand disability-insurance), and the like. Furthermore, there seems to be no limit to the public's appetite for publicization. Consider currently-fashionable proposals to convert, e.g., basic income, employment, and even broadband access into public goods. To illustrate with just one example: when WiFi first began to appear in private homes and selected public spaces, very few (if any) partisans of the Public Interest seriously advocated for its guaranteed, universal state provision; indeed, such claims might have been dismissed out-of-hand with a laugh. Today, though, just over 15 years later, matters stand quite differently. No longer does the notion of guaranteed universal WiFi seem quite so much like a reductio ad absurdum: various parties sincerely assert the moral imperative of guaranteeing, e.g., broadband access, or even WiFi coverage, for all citizens. (Consider, for example, the position of Martin O'Malley-former governor of the state of Maryland, and once (and future?) candidate for U.S. President. ${ }^{16}$ And the United Nations adopted a resolution in 2016 declaring

16 As detailed at https://www.washingtonpost.com/news/the-fix/wp/2014/10/08/martin-omalley-and-the-humanright-to-wifi/?utm term=.851d94a03f09 (accessed November 2, 2019). 
that Internet access is a human right. ${ }^{17}$ ) So if we can publicize any good, the argument that 'the state is necessary in order to provide us with public goods' obviously requires serious re-examination.

But why not think that the Worthy PGA is worthy of this challenge? Why not conclude that it is the version of the PGA that emerges from this very re-examination? Why not assume that CBA provides our means of distinguishing the worthy from the unworthy public goods-publicized goods no less than inherently public ones-such that the Worthy PGA dispatches with even the new-and-improved promiscuity problem? Well, the worry is that-though for any particular proposed publicized good, CBA might offer a perfectly sensible technique for ascertaining the propriety of state provision of said good-as a matter of general policy, CBA is powerless to offer us any systematic vision or guidance as to the proper scope of the state's public-goodprovisioning activities. And this is because under such a policy, CBA would have, simply put, far too much work to do.

Consider: in implementing said policy, we would presumably start by selecting a plausible range of private goods, and begin performing CBAs on various proposals to publicize them. What would these analyses reveal? It might seem difficult to make any ex ante forecasts about the systematic results of such a program of comprehensive analysis. Surely, for some goods that could otherwise remain private (that is: goods for which spontaneous marketplace provision at something like efficient levels might be expected), cost-benefit analyses would reveal that publicization is worth the cost; for other goods, it may prove more socially profitable to retain their provision within the private sector. Still other goods may resist entirely any such analysis in costbenefit terms. (This seems to be the case especially when we begin to think about entrepreneurship: how could the full costs and benefits of innovative new products and services be fully anticipated, let alone precisely measured and traded off against one another?)

Fortunately, we need not traffic in such ex ante speculations about the principal drift of such a program. We need not attempt to undertake even just a sampling of such cost-benefit analyses to answer this question. We need rather note here only one quite general 'cost' of the CBA-centered approach-what we might term its computational cost. For consider now more fully just what such a program would look like. The Worthy PGA sanctions state provision of every cost-effective public good-meaning that a CBA would have to be performed for every candidate public good, including every candidate publicized good. So far, so good. But the set of candidate publicized goods is not (as you may have initially assumed) exhausted by the set of all private goods (and services) currently on offer in the marketplace. It does include all these goods and services, obviouslyand performing the requisite CBAs for just this set of goods would already be quite a drastic undertaking.

\footnotetext{
${ }^{17}$ Available at https://www.article19.org/data/files/Internet_Statement Adopted.pdf (accessed November 2, 2019).
} 
(We would have to ascertain whether the social benefits exceed the social costs for fully publicizing, e.g., housing, employment, personal communication devices and other forms of information technology, broadband and WiFi, healthcare, insurance, spiritual and intellectual enrichment, food, clothing, entertainments and diversions, transportation, education ... the list goes on and on.) But this is only the tip of the iceberg. For the set of candidate publicized goods includes not only all those private goods that already are being provided at efficient, equilibrium levels by market actors; it includes as well all the possible, nonactual (but still technologically feasible) private goods that are not being provided by the private sector. For, for any such good, we could never know for certain (until we'd crunched the numbers via CBA) whether its non-provision by market actors is due only to the same sort of market failure that precludes private provision of public goods-viz., that, even though the social benefits of its universal provision would exceed its social costs, potential suppliers could not expect to recoup their costs, leaving the socially-beneficial good to remain nevertheless un-provisioned. And this is a market failure that, according to the PGA's proponents, the state can and should correct. ${ }^{18}$

Consider further just what such CBAs would entail. Besides the identification of a (real or hypothetical) private good to serve as a candidate for publicization, each CBA would also need to identify a proposal-nay, a range of proposals-for various ways in which this good might be publicly provisioned. Only then could state officials attempt to precisely forecast the full range of benefits and costs (including opportunity costs) associated with each practicable method of state provision of said good, and to assess the magnitude of the difference between prospective costs and benefits. And only then could state officials make a determination as to whether there is a proposed provisioning scheme according to which it makes sense to publicize the candidate good. This process would have to be repeated, not only for every good already provided by the private sector, but also for every potential (technologically feasible) good and service not currently appearing in the marketplace.

\footnotetext{
${ }^{18}$ For example: imagine that a team of researchers were confident that it is within our technical capacity to formulate and manufacture an entire regimen of super-delicious, super-nutritious, wholly synthetic food. It will not be cheap to get there, however: though our current grasp of chemistry and metabolism and so forth is sufficient to abet its discovery, the recipes for these products will not be discovered without considerable investment in research and development $(R \& D)$ activities. Furthermore, even once discovered, it is unclear whether production of these synthetic foods would be profitable. (Perhaps they are difficult and expensive to manufacture; perhaps their recipes would be sufficiently easy to reverse-engineer that investors would have little confidence that even the most robust intellectual property protections could prevent pirated versions of the product from appearing on the market.) These anticipated challenges might preclude private investment in the $R \& D$ necessary to produce these synthetic superfoods. However, sufficiently widespread uptake of a synthetic-superfoods-centric diet might generate enormous social benefits that would go largely unrecouped by their manufacturers: it might significantly decrease the incidence of industrialized agriculture (resulting in drastic reductions in $\mathrm{CO}_{2}$ emissions and nitrogen run-off, and freeing up considerable land for re-forestation); it might generate enormous public health benefits (by significantly decreasing the incidence of, e.g., cancer, obesity, and diabetes); etc. In such a scenario, a CBA might commend that these synthetic superfoods be publicized, though (in a sense) they had never even been 'privatized'.
} 
Obviously, this approach would saddle the government with enormous computational costs. And these costs cannot be lessened by citing standard economic doctrine regarding market efficiency as a reason to dispense with performing CBAs for goods already provided by the private sector. For consider the following sort of objection: 'For goods currently being provided at efficient, equilibrium levels by market actors, we would not actually need to perform a CBA to ascertain the cost-effectiveness of their publicization. For, given some famous theorems in neoclassical economics, the fact that said goods are already being provided via market actors is ipso facto evidence that they are being provided as efficiently as possible-that both consumer and producer surplus are being maximized. There is no room for further improvement in economic efficiency with respect to the provisioning of such goods, by state actors or otherwise. Thus, we need not bother applying the CBA framework to any of these goods.' This objection suffers from one obvious defect: the failure to distinguish some (ex hypothesi efficiently-produced) private good from the (clearly related, but analytically distinct) publicized good that results from, e.g., guaranteeing universal access to that private good. ${ }^{19}$ For even if we take extant market provision of some private good as evidence that state intervention need not be taken with respect to its provision (indeed could not be undertaken, at least not with comparable efficiency), it's a separate question (to be answered by CBA, presumably) whether state intervention might, in sociallyprofitable fashion, be undertaken to secure the public good of universal access to that private good. ${ }^{20}$ But leaving this defect to one side for the moment: even were it successful, this 'markets-are-efficient' objection does little to mitigate the force of the Worthy PGA's 'computational intractability' problem. For at best it would demonstrate that such CBAs need not be performed for one subset of the class of candidate publicized goods: those that result from publicizing extant private goods (and services). There still remains the enormous additional subset of candidate goods (arguably much larger!) comprising all the technologically feasible, possible-but-not-actual goods. The existence of this set of candidate goods alone is seemingly enough to render a CBA-centered solution to (the stronger version of) the promiscuity problem computationally intractable.

To recap: proponents of the PGA standardly invoke a series of highly desirable (perhaps even indispensable?) public goods in an effort to lend intuitive force to their view: 'Who wouldn't want clean air and water, national

\footnotetext{
${ }^{19}$ In the terminology developed in note 9 above, this objector has failed to distinguish $g$ from $\mathrm{G}$.

${ }^{20}$ To illustrate how this might play out, note that some folks might value $G$ in ways that are relatively independent of the way they value $g$, so their willingness-to-pay for the former may be quite independent of their willingness to pay for the latter. Consider as an example unemployment insurance as a $g$, and its potentially universal provision as a G. I may be willing to pay a given premium to ensure for myself a certain amount of income maintenance in the event of involuntary unemployment-but I may also be willing to pay an additional premium as part of a scheme ensuring that I live in the sort of polity where everyone enjoys such indemnity, irrespective of their own ability and/or willingness to pay for it.
} 
defense, law and order, public highways and bridges, and the like? But these are all public goods-nonexcludable in character-and thus we can't expect the market to provide them. Therefore we need the state to do so.' However, many of the public goods thus invoked are in fact publicized goods rather than inherently public goods. (In the list just offered, it seems clear that highways, bridges, and likely even (the subcomponents of) law and order fall into this category of publicized goods.) This fact has heretofore underappreciated consequences for the PGA.

The main consequence, explored thus far in this paper, can now be given pithy expression in the form of a dilemma: in their defense of the argument, proponents of the PGA may either (i) abjure appeal to publicized goods altogether, restricting their invocations of illustrative examples to the set of inherently public goods; or (ii) continue to invoke publicized goods alongside inherently public ones, thereby purchasing for the PGA an extra degree of plausibility. If they opt for the former horn of the dilemma, the PGA's proponents must sacrifice some of the argument's intuitive appeal. If they opt for the latter horn, they may continue to leverage popular sentiment in favor of government provision of, e.g., the social safety net-but they also must contend with the PGA's promiscuity: the fact that it can, in principle, license state provision of all manner of goods.

The PGA's promiscuity has not gone thus far entirely unnoticed, however. Indeed, it is commonplace for writers in this tradition to address themselves to a milder form of the promiscuity problem-for many authors acknowledge that a fully-fledged PGA must include criteria for identifying which of the possible public goods are worthy of state provision. (That is, they acknowledge that not every public good-not every good bearing the requisite formal property of non-excludability-is one that the state ought to provide.) And it is just as commonplace for authors to supply just such a criterion: cost-benefit analysis as a means of determining which candidate public goods provide social benefits sufficient to justify their social costs.

However, while CBA might be adequate to address the milder form of the promiscuity problem arising when we consider just the inherently public goods, it is ill-equipped to defuse the stronger version of the problem that arises once we fully consider the possibility of publicization. This is because a fully-fledged CBA-centered approach to identifying the cost-effective publicized goods is computationally intractable: cost-benefit analyses would have to be performed for each member of the set of candidate publicized goods-and as we have just seen, this set (even were we to exclude from it all the goods currently provisioned by the private sector) turns out to be quite extensive indeed.

So it appears that defenders of the PGA must either abjure any appeal to publicized goods-thus forfeiting much of the argument's intuitive appeal-or admit the need for a computationally intractable strategy for defusing the promiscuity problem that arises as a result of their invoking publicized goods alongside 
inherently non-excludable ones in the PGA's defense. In either event, though, it seems that the PGA must be substantially reconceived, and that the PGA's proponents have their work cut out for them.

This may seem an unwelcome development for partisans of the PGA, and in presenting this dilemma I may therefore seem to be unfriendly to their cause. But it is not, and I am not. It is, rather, an opportunity to improve the PGA, and ultimately I raise it only in hopes of identifying and developing satisfactory strategies for its dissolution. So I shall end on a note that is slightly less pessimistic and more constructive. In the paper's brief closing section, I explore some potential directions for future research-promising visions for how just such a 'substantial reconception' of the PGA might be achieved.

\section{Concerning the PGA's Prospects}

Since, as we have stressed, many private goods have already been publicized, the PGA's proponents might begin the task of reconceiving their argument by looking to tradition, received custom, and current practice. By studying cases where publicization is already a fait accompli, we may be able to ascertain whether certain principles or guidelines are already latent in our extant practices of publicization. Even if not explicitly formulated in terms of the 'promiscuity problem', and even if not explicitly addressed in terms of achieving 'computationally tractable' solutions, there is a sense in which policy-makers have formulated these problems and institutions have evolved to address them. For clearly a range of decisions on these matters has already been effected: some goods have been publicized, and others have not. Perhaps even there have been cases where the possibility of publicizing some private good has been raised and duly considered, but ultimately rejected. It might be, therefore, that policy-makers have relied (perhaps implicitly) on some set of principles that have led them to favor publicization of some goods and not others.

For example: private goods sometimes seem to have been publicized because they are deemed fundamental to the enjoyment of some kind of minimum acceptable standard of living, and are not affordable to some significant portion of the population. At the same time, there must be more to it than this 'minimumstandard-of-living principle', because we do not typically publicize private goods such as furniture, though it certainly must be considered part of a minimum standard of living. For those who cannot afford tables and chairs, we typically prefer cash assistance of some kind, rather than the essentially paternalistic assistance implied by publicization. So why do we choose publicization in some cases and cash assistance in others? Perhaps the discerning analyst might discover reasoned distinctions and principles that have guided past practice in this regard; in this way, perhaps, the PGA might be augmented by being conjoined with these principles. On the theory that historical or traditional approaches to publicization embody at least some degree of internal logic, coherence, and practical wisdom, we might seek guidance in historical pedigree. In recognition of the fact that this approach represents something of a hybrid of various 'respect-for-historical- 
pedigree insights' commonly associated with thinkers like Edmund Burke and Friedrich Hayek, we might call this the 'Hay-Burkean Approach'. ${ }^{21}$

An alternative approach takes inspiration from John Rawls and Knut Wicksell, rather than from Burke and Hayek. Building off of a suggestive though little-discussed passage in $\$ 43$ of Theory of Justice, PGA proponents might develop a fully-fledged theorization of Rawls's contemplated 'Exchange Branch' of government. This specialized organ of the state would be dedicated to the task of winnowing the set of possible public(ized) goods down to a subset sufficiently small that a CBA might feasibly be performed for each of its members. Exchange Branch officials might utilize public input and various heuristics to perform this winnowing task. (They might further employ some relatively 'cutting-edge' techniques in this regard, such as quadratic voting and quadratic funding. ${ }^{22}$ ) In all likelihood, the Exchange Branch would employ some sort of 'supermajoritarian threshold' to public demand for candidate goods, even if this threshold might fall slightly short of the Wicksellian 'unanimity criterion' that Rawls contemplates in Theory. ${ }^{23}$ In recognition of the fact that this approach takes inspiration from both Rawls and Wicksell, we might call this the 'Rawl-sellian Approach'.

I grant that my sketches of the Hay-Burkean and Rawl-sellian approaches represent only the barest, most programmatic sketches of two possible directions for future research. Whichever direction(s) this further development of the (Worthy) PGA takes, however, it seems clear that it must be reconceived so that the burden of proof has been thusly shifted: a good's non-excludability is no longer seen as a presumption in favor of its state provision; rather, a good's 'publicness' must now be seen merely as rendering a good eligible for state provision. However, absent further demonstration of that good's Worthy-ness (a demonstration that might proceed along lines embodied in either the Hay-Burkean or Rawl-sellian approaches), that is all that it does. Nevertheless, the foregoing sketches offer two possible directions (and likely there are others) for future investigation as to how the publicized goods that have been our concern in this paper need not concern the proponent of the PGA any more than necessary. ${ }^{24}$

\section{Works Cited}

Anomaly, Jonathan [2015]. "Public Goods and Government Action.” Politics, Philosophy E\& Economics 14(2): 109-28.

\footnotetext{
${ }^{21}$ I am greatly indebted to a reviewer from Economics and Philosophy for raising to my attention the possibility of this approach, and for much of its present formulation. (This reviewer may or may not approve of my own characterization of this approach as 'Hayekian' or 'Burkean', however!)

${ }^{22}$ For one recent discussion of quadratic voting (a new name for a technique first developed in the 1960s by economist William S. Vickrey), see e.g. chapter 2 of Posner and Weyl [2018].

${ }^{23}$ The relevant discussion appears at Rawls [1999: 249-51]; Wicksell's criterion is mentioned at p. 249 , note 19.

24 For comments on drafts of this paper (and/or its various predecessors), I am grateful to Jonathan Anomaly, Christopher Freiman, Brian Kogelman, Dan C. Shahar, and an anonymous reviewer for Economics and Philosophy.
} 
[2018]. "Public Goods and Education." In Philosophy and Public Policy, ed. Andrew I. Cohen. London: Rowman \& Littlefield: 105-20.

Baumol, William J. [1965]. Welfare Economics and the Theory of the State, reissued with a new introduction. Cambridge, MA: Harvard University Press.

Baumol, William J., and Alan S. Blinder [2006]. Economics: Principles and Policy (10 ${ }^{\text {th }}$ Edition). Boston, MA: Cengage Learning.

Buchanan, James [1968]. The Demand and Supply of Public Goods. Chicago: Rand McNally.

Coleman, Jules [1985]. "Market Contractarianism and the Unanimity Rule." Social Philosophy and Policy 2(2): 69-114.

Cornes, Richard, and Todd Sandler [1996]. The Theory of Externalities, Public Goods and Club Goods, $2^{\text {nd }}$ edition. Cambridge, UK: Cambridge University Press.

Cowen, Tyler [2003]. “The Public Goods Rationale for Government and the Circularity Problem.” Politics, Philosophy E Economics 2(2): 265-77.

[2008]. "Public Goods." In The Concise Encyclopedia of Economics, ed. David R. Henderson. Indianapolis: Liberty Fund. Reprinted in Anomaly et. al. [2016], 197-9.

Freiman, Christopher [2017]. Unequivocal Justice. New York: Routledge.

Goldin, Kenneth D. [1977]. "Equal Access vs. Selective Access: A Critique of Public Goods Theory.” Public Choice 29(1): 53-71.

Hampton, Jean [1987]. "Free Rider Problems in the Production of Collective Goods." Economics and Philosophy 3(2): 245-73. Reprinted in Anomaly et. al. [2016], 241-55.

Hasnas, John [2008]. “The Obviousness of Anarchy.” In Anarchism/Minarchism: Is a Government Part of a Free Country?, Roderick T. Long \& Tibor R. Machan, eds. Aldershot: Ashgate, 111-31. 
Head, J. G. [1962]. "Public Goods and Public Policy.” Public Finance 17(3): 197-219.

Huemer, Michael [2013]. The Problem of Political Authority. New York: Palgrave Macmillan.

Mueller, Dennis [1989]. Public Choice II: A Revised Edition of Public Choice. New York: Cambridge.

Musgrave, Richard A. [1959]. The Theory of Public Finance: A Study in Public Economy. New York: McGraw Hill.

Ostrom, Elinor [2000]. "Collective Action and the Evolution of Social Norms." Journal of Economic Perspectives 14(3): 137-58.

Ostrom, Vincent, and Elinor Ostrom [1977]. "Public Goods and Public Choices." In Alternatives for Delivering Public Services: Toward Improved Performance, ed. E. S. Savas. Boulder: Westview Press, 7-49.

Posner, Eric A., and E. Glen Weyl [2018]. Radical Markets: Uprooting Capitalism and Democracy for a Just Society. Princeton, NJ: Princeton University Press.

Rawls, John [1999]. A Theory of Justice (Revised Edition). Cambridge, MA: Harvard.

Samuelson, Paul A. [1954]. "The Pure Theory of Public Expenditure." The Review of Economics and Statistics 36(4): $387-9$.

[1955]. "Diagrammatic Exposition of a Theory of Public Expenditure." The Review of Economics and Statistics 37(4): 350-6.

Schmidtz, David [1991]. The Limits of Government: An Essay on the Public Goods Argument. Boulder, CO: Westview.

Taylor, Michael [1987]. The Possibility of Cooperation. New York: Cambridge University Press. 